\title{
EFFECT OF GEOMETRY COMPUTATIONS AND NUMERICAL SCHEME ON THE RESISTANCE COEFFICIENT FOR UNSTEADY FLOW IN IRREGULAR CHANNELS
}

\author{
Moustafa A. El-Enany \\ Assistant Prof., Dept. of Civil Eng., Faculty of Engineering, \\ Menufiya University, Shebin El-Kom, Egypt.
}

\begin{abstract}
The problem of predicting flow resistance coefficient with sufficient accuracy is of great interest to hydraulic engineers. Realistic estimate of hydraulic resistance is important to the proper design and analysis of irrigation and drainage networks. Resistance (roughness) coefficient is a compound function of the geometric properties of the channel, the fluid properties, and the varied flow conditions prevalent in the open channel system. The purpose of this study is to demonstrate the response of the applied method of irregular geometric properties computation, the used numerical scheme, and the distance interval adopted in the numerical model on the calibrated value of resistance coefficient.

The rectangular grid scheme of the method of characteristics is applied with different methods of irregular geometric properties computation and different value of distance interval. While, the Leap-Frog finite difference scheme is used with only one method of geometric properties computation and one value of distance interval. Measured field data of Tanta Navigation canal are used to feed and calibrate the numerical models. Results of numerical experiments illustrate that inaccurate channel geometry representation in the numerical models leads to incorrect value for the calibrated value of roughness coefficient. Findings also demonstrate that the applied numerical scheme as well as the schematization to describe the channel geometry by a series of discrete representation along the reach being modeled has significant effect on the calibrated value of the roughness coefficient.
\end{abstract}

Manuscript received from Dr . Moustafa A. El - Enany

Accepted on : $7 / 9 / 2002$

Engineering Research Journal Vol 25, No 4, 2002 Minufiya University, Faculty Of Engineering, Shebien El-Kom, Egypt, ISSN 1110 1180 
The main issue of the problem of flow in alluvial channels centers on the estimation of their hydraulic resistance. Knowledge of this factor is essential for accurate calculation of the sediment transport rate, stage-discharge relationships, channel stability, waterways design, and prediction of aggradation and degradation due to the presence of hydraulic structures. The resistance (roughness) coefficient is influenced by size, shape, and arrangement of granular material forming the wetted perimeter, geometry of the bed patterns (ripples, dunes, and antidunes) formed by the flow, rate of sediment transport, irregularity of channel cross sections, variation of shape and size of channel cross sections, channel alignment (meandering), vegetation characteristics and obstructions [14]. Each of these components contributes to the total resistance coefficient.

One of the characteristics of irregular channels is the geometric properties variation of cross sections, Area (A), top width (B), and wetted perimeter (P), along the channel reach. The non-uniform properties of channel cross sections (channel irregularity) affect the conveyance and storage characteristics of the channel reach. Channel irregularities control the variation of flow from section to section and, at particular section, the variation of flow with stage. Theses irregularities are directly responsible for modifications of flow characteristics along the channel reach. The measured cross sections of irregular channel must be chosen to ensure excellent feeding of the geometrical characteristics into the numerical model. They must be specified at locations along the channel reach where significant cross sections changes occur, i.e. the spacing of the measured cross sections, $\Delta X$, depends on the degree of variation of cross section characteristics. Often this is a matter of economic balancing the value of additional accuracy versus the additional costs of data acquisitions.

The user of a computer program must decide the distance interval, $\Delta \mathrm{X}$, to be used in the computation and whether some of cross sections should be deleted (i.e., using larger distance interval) or additional ones introduced (say be interpolation). It is generally true that using smaller value of distance interval (step) in the numerical solution tends to give better accuracy, but requires more computation time [10 and 20]. There are different methods to simulate the measured geometric properties of cross sections in the numerical model. The numerical model user must consider how best to embody the physical characteristics and properties of the prototype system to the model.

The objective of this research is to study the effect of the used method for treatment of the measured geometric properties, the used distance interval, and the applied numerical scheme on the calibrated value of roughness coefficient. Numerical experiments are implemented using the rectangular grid scheme of the method of characteristics and the Leap-Frog scheme. Different methods of treatment of irregular geometric properties and different values of distance 
interval are applied. Measured field data of Tanta Navigation canal are used to carry out the numerical experiments.

\section{Pervious Work}

Most of the pervious researches used the calibration process to get the optimum value of the roughness coefficient, $(n)$. Some of the pervious researches calibrated the roughness coefficient as a constant value $[5,9,10,16,17,18,22$, 24 , and 26), or as a function of the longitudinal distance along the study reach (X) $[3,5,12,16$, and 23]. While others calibrated the roughness coefficient as a function of the discharge (Q) $[13,17$, and 20], as a function of the water depth (y) [19 and 26], or as a function of X and $\mathrm{y}$ [25]: It is fourid that the calibrated value of roughness coefficient is highly affected by the used boundary conditions [24] and including or omitting the non-prismatic term in the governing equations of unsteady flow [22].

Also, it is concluded that the measured field data errors and the local hydraulic conditions at the gauge site significantly influence the calibrated value of roughness coefficient [18]. Other researches calculated the value of roughness coefficient using measured field data of geometric properties, velocity (V) and water surface slope (S) at some selected cross sections along the study reach and applying Manning or Chezy equation [1, 6, 7, 8, 11 and 15]. While another research calculated the value of roughness coefficient in terms of the type of boundary material and bed forms at each measured cross section [10].

Various methods have been applied to represent the cross-sectional properties of irregular channels in the numerical models. Three board groups may be distinguished as follows:

1- using exact method, which calculates the geometric properties (A, P, and $B)$ at each measured cross section for any value of water depth [10];

2- replacement of the actual irregular channel by only one cross section defined by regular shape of rectangular or trapezoidal cross section [ 26 and 27], or by cross-sectional properties defined by table of y versus $A$, $P$, and $B$ or developed relationships of y versus $A, P$, and $B[3,10,17$, and 19];

3- replacement of the measured cross sections by cross sections defined by regular shape $[12,18$, and 26$]$, by tables of y versus $A, P$, and $B$ at each sections $[2,9$, and 10$]$, or by developed relationships of $y$ versus $A, P$, and $B$ at each section $[3,4$ and 10$]$.

\section{Governing Equations}

The unsteady one-dimensional open channel flow equations can be derived from the principles of conservation of mass and momentum. The resulting equations are hyperbolic, non-linear, first order partial differential equations known as the 
de Saint Venant equations [21]. They can be expressea in terms or verocity ana water depth as dependent variables as follows [21]:

$$
\begin{aligned}
& A \frac{\partial V}{\partial X}+V B \frac{\partial y}{\partial X}+B \frac{\partial y}{\partial t}+V\left(\frac{\partial A}{\partial X}\right)_{y}=0 \\
& \frac{\partial y}{\partial X}+\frac{V}{g} \frac{\partial V}{\partial X}+\frac{1}{g} \frac{\partial V}{\partial t}=S_{o}-S_{f}
\end{aligned}
$$

in which; $\mathrm{A}$ is the cross-sectional area; $\mathrm{V}$ is the velocity; $\mathrm{B}$ is the canal top width at the water level; $X$ is the longitudinal distance along the study reach; $y$ is the water depth; $t$ is the time; $S_{O}$ is the bed slope; and $S_{f}$ is the friction slope which calculated by Manning or Chezy equation, and $\left(\frac{\partial A}{\partial X}\right)_{y}$ is the nonprismatic term $=$ rate of variation of $A$ with respect to $X$ when y is kept constant.

If the discharge and the cross-sectional area are used as dependent variables, the governing equations are expressed as follows[21]:

$$
\begin{aligned}
& \frac{\partial A}{\partial t}+\frac{\partial Q}{\partial X}=0 \\
& \frac{\partial Q}{\partial t}+\frac{\partial}{\partial X}\left(\frac{Q^{2}}{A}+g A Y_{c . g}\right)=\dot{g} A\left(S_{o}-S_{f}\right)
\end{aligned}
$$

in which; $\mathrm{Q}$ is the discharge and $\mathrm{Y}_{\mathrm{c.g}}$ is the depth of centroid of water section below water surface.

\section{Models Used in Numerical Experiments}

In this study, two numerical methods are used to solve the governing equations of unsteady flow in open channels. The first one is the rectangular grid scheme of the method of characteristics, MOC. While, the second one is explicit finite difference method (Leap-Frog Scheme).

\section{Method of Characteristics (MOC)}

Equations ( 1 and 2) can be written in the characteristic form as follows [10]:

$$
\frac{d X}{d t}=V \pm C
$$




$$
\frac{1}{g} \frac{d V}{d t} \pm \frac{1}{C} \frac{d y}{d t}=S_{o}-S_{f} \mp \frac{V C}{g A}\left(\frac{\partial A}{\partial X}\right)_{y}
$$

in which; $\mathrm{C}$ is the wave celerity $=(\mathrm{gA} / \mathrm{B})^{0.5}$

Using the first order approximation, i.e., explicit solution, and the tectangular grid scheme of the method of characteristics, the characteristic equations can be: written as:

$$
\begin{aligned}
& X_{P}-X_{R}=(V+C)_{R}\left(t_{P}-t_{R}\right) \\
& X_{P}-X_{S}=(V-C)_{S}\left(t_{P}-t_{S}\right) \\
& V_{P}-V_{R}+\frac{g}{C_{R}}\left(y_{P}-y_{R}\right)-g\left(S_{o}-S_{f R}\right)\left(t_{P}-t_{R}\right)+g\left(\frac{V_{c}}{g A}\right)_{R}\left(\frac{\partial A}{\partial X}\right)_{y}\left(t_{P}-t_{R}\right)=0 \\
& V_{P}-V_{S}-\frac{g}{C_{S}}\left(y_{P}-y_{S}\right)-g\left(S_{o}-S_{f S}\right)\left(t_{P}-t_{S}\right)-g\left(\frac{V c}{g A}\right)_{S}\left(\frac{\partial A}{\partial X}\right)_{y}\left(t_{P}-t_{S}\right)=0
\end{aligned}
$$

in which the subscripts indicate the point in Fig. (1) at which quantity is referred. The variables $V, R$ (hydraulic radius), $C$ (wave celerity), and $y$ at the points $R$ and $S$, Fig. (1), are calculated by interpolation between the adjacent nodes. By solving the above equations, the values of $V_{p}$ and $y_{p}$ can be obtained.

\section{Leap-Frog Scheme}

This scheme is explicit finite difference scheme, which is of second order accuracy. Equations (3 and 4) are expressed in finite difference [21] as follows, Fig. (1):

$$
\begin{aligned}
& \frac{A_{i}^{j+1}-A_{i}^{j-1}}{2 \Delta t}+\frac{Q_{i+1}^{j}-Q_{i-1}^{j}}{2 \Delta X}=0 \\
& \frac{Q_{i}^{j+1}-Q_{i}^{j-1}}{2 \Delta t}+\frac{F_{i+1}^{j}-F_{i-1}^{j}}{2 \Delta X}=E_{i}^{j}
\end{aligned}
$$

in which; $\mathrm{F}=\left(\mathrm{Q}^{2} / \mathrm{A}+\mathrm{gA} \mathrm{Y}_{\mathrm{c} . \mathrm{g}}\right) ;$ and $\mathrm{E}=\mathrm{gA}\left(\mathrm{S}_{\mathrm{o}}-\mathrm{S}_{\mathrm{f}}\right)$

Equations (11 and 12) yield expressions for $A$ and $Q$ at the $(j+1)$ th time level in terms of the dependent variables at the (j)th and (j-1)th time levels. Equations (11 and 12) are linear equations, which can be solved easily.

\section{Field Data}

The purpose of field measurements is to feed and calibrate the numerical model. In this research, a reach of $15-\mathrm{km}$ length of Tanta Navigation canal, from $\mathrm{km} 0.0$ 
to $\mathrm{km} 15.0$, is chosen to measure the treld data requirea tor the numerical inuuel. This reach of the canal is located in Al-Menufiya Governrate. This canal is stable alluvial canal, which takes water from Bahr Shebin at km. 53.50, Fig. (2). The geometric properties of cross sections for the study reach are measured at equal distance of $1 \mathrm{~km}$. For each cross section, the level of canal bed and its sides are measured every $2 \mathrm{~m}$ along the canal sections, Figs ( 3 and 4 ) are examples of the measured cross sections.

The flow is assumed to be steady nonuniform at the initial line, at time $(\mathrm{t})=0$, to get the initial water depth at all cross sections along the study reach. This is carried out by employing Manning's equation with the same roughness coefficient and the same method of geometric properties simulation used in the numerical model. Daily water level hydrograph at downstream boundary of the study reach is measured through a period of 21 days. Daily water level and discharge hydrographs at the upstream boundary of the study reach are obtained from the Ministry of Water Resources and Irrigation. Daily discharge hydrograph at a section of $6 \mathrm{~km}$ away from the upstream boundary is measured through a period of 21 days, Fig. (7).

The mean velocities of canal cross section are measured using a marked wire and the currentmeter. The cross section is divided into a number of subsections of width $5 \mathrm{~m}$. The mean velocity of each subsection is measured with the currentmeter. For shallow depths, the mean velocity is considered to be equal to the measured velocity at 0.6 water depth measured from the water surface. While for other depths, the mean velocity is considered to be equal to the average of the measured velocities at 0.2 and 0.8 water depth below the water surface. Least square method is used to get the longitudinal bed slope, which is $6.4 \mathrm{~cm} / \mathrm{km}$.

\section{Numerical Experiments}

In this study, the rectangular grid scheme of the method of characteristics is applied using distance interval of $2 \mathrm{~km}$ and different methods to simulate the measured geometric properties of the study reach. These methods are as follows: 1- using exact method, which calculates the geometric properties $(\mathrm{A}, \mathrm{P}$, and $B$ ) at each measured cross section for any value of water depth, $y$;

2- replacement of each measured irregular cross section by cross-sectional properties defined by table of $y^{\prime}$ versus $A, P$, and $B$;

3- replacement of each measured irregular cross section by developed relationships of $y$ versus $A, P$, and $B$;

4- replacement of the measured irregular cross sections by only one cross section defined by developed relationships of $y$ versus $\mathrm{A}, \mathrm{P}$, and $\mathrm{B}$; and 
5- by using a newly developed method, which replace each measured irregular cross section by developed relationships of $y$ versus A, P, and B as follows:

- Divide each measured cross section into two parts; the first part is below the minimum expected water level, while the second part is above the, minimum expected water level, Fig. (5);

- Using the exact method (method No.1 mentioned above), calculate the area $\left(A_{0}\right)$, the wetted perimeter $\left(\mathrm{P}_{0}\right)$, and the top width $\left(\mathrm{B}_{0}\right)$ for the first part of the measured cross section corresponding to the expected minimum water level ;

- Develop relationships (functions), of $y_{U}$ versus $A, P$, and $B_{U}$, for the second part of the measured cross section, Fig. (5):

$$
A=f_{1}\left(y_{U}\right), P=f_{2}\left(y_{U}\right), \quad B_{U}=f_{3}\left(y_{U}\right)
$$

Where; $y_{U}$ is any value of water depth above the expected minimum water level and $\mathrm{B}_{U}$ is the increase in top width corresponding to $\mathrm{y}_{U}$.

These functions are obtained by assuming different values of $y_{U}$ above the minimum expected water levels and calculating the corresponding values of $\mathrm{A}, \mathrm{P}$, and $\mathrm{B}_{\mathrm{U}}$ by using the exact method (method No.1 mentioned above).

- For each measured cross section, the values of A, P, and B (for the first and the second part of the section, i.e., for the whole section) at any value of $\mathrm{y}$ are calculated as:

$$
A=A_{0}+f_{1}\left(y_{U}\right), P=P_{0}+f_{2}\left(y_{U}\right), B=B_{0}+f_{3}\left(y_{U}\right)
$$

It is worth to mention that the above mentioned methods (method No.2 to method No.5) apply method No.1 to form the tables or to develop the relationships of $y$ versus $A, P$, and $B$. The above mentioned methods are labeled herein as method1, method2, method3, method4, and method5; respectively.

Also, different values of distance interval are applied using the rectangular grid scheme with the two cases of measured geometric properties computation; casel and method4. The used values of distance interval are $1 \mathrm{~km}, 2 \mathrm{~km}$, and $3 \mathrm{~km}$, i.e., it is assumed that the information of the measured cross section is only available at distances of $1 \mathrm{~km}, 2 \mathrm{~km}$, and $3 \mathrm{~km}$; respectively. The Leap-Frog scheme is applied using method1 of measured geometric properties computation with distance step of $2 \mathrm{~km}$.

\section{Method of Accuracy Assessment}

In this study, the results of numerical experiments are compared with the measured discharge hydrograph at $\mathrm{km} 6$. The accuracy refers to how closely the computed values agree with the measured field values. This means that the difference between the simulated results of a certain numerical solution and the measured values is a measure of accuracy of that solution. This difference (error) is expressed in mean of the percentage relative errors, where; 
Percentage relative error $=100 * \mid$ measured value - calculated value $\mid /$ (measured value)

The statistical methods used in this study are percentage relative accuracy and standard deviation of the percentage relative errors (S.D.), where;

Percentage relative accuracy $=100-$ mean of percentage relative errors;

While the mean of percentage relative errors is defined as the summation of the percentage errors divided by the number of observations.

\section{Analysis of the Numerical Results}

The results of the numerical experiments applying the rectangular grid scheme of the method of characteristics with different methods of geometric properties computation and distance interval of $2 \mathrm{~km}$ are shown in Table (1).

Table (1) Effect of using different methods of geometric properties computation on the calibrated value of roughness coefficient.

\begin{tabular}{|c|c|c|c|c|c|c|}
\hline \multirow{3}{*}{$\begin{array}{l}\vec{Z} \\
\stackrel{8}{0} \\
\stackrel{8}{0}\end{array}$} & Value of $n$ & 0.027 & 0.0275 & 0.028 & 0.0285 & 0.029 \\
\hline & $\begin{array}{l}\% \text { relative } \\
\text { accuracy }\end{array}$ & 95.8913 & 96.1837 & 96.3853 & 96.2067 & 96.0171 \\
\hline & S.D. & 0.8492 & 0.8238 & 0.8035 & 0.8217 & 0.8483 \\
\hline \multirow{4}{*}{ 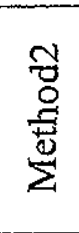 } & Value of $n$ & 0.0275 & 0.028 & 0.0285 & 0.029 & 0.0295 \\
\hline & $\begin{array}{l}\% \text { relative } \\
\text { accuracy }\end{array}$ & 95.4053 & 95.6019 & 95.7925 & 95.5973 & 95.3868 \\
\hline & S.D. & 0.8901 & 0.8703 & 0.8518 & 0.8723 & 0.8917 \\
\hline & \multicolumn{6}{|c|}{ Comutation time $=49.26 \%$ of that of methodl } \\
\hline \multirow{4}{*}{ 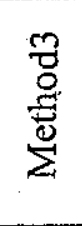 } & Value of $n$ & 0.028 & 0.0285 & 0.029 & 0.0295 & 0.030 \\
\hline & $\begin{array}{l}\% \text { relative } \\
\text { accuracy }\end{array}$ & 94.9088 & 95.1339 & 95.3830 & 95.1467 & 94.9173 \\
\hline & S.D. & 0.9175 & 0.8946 & 0.8706 & 0.8937 & 0.0 .9165 \\
\hline & \multicolumn{6}{|c|}{ Comutation time $=34.38 \%$ of that of method 1} \\
\hline \multirow{4}{*}{$\begin{array}{l}\text { 吾 } \\
\text { 总 } \\
\stackrel{0}{\Sigma}\end{array}$} & Value of $n$ & 0.030 & 0.0305 & 0.031 & 0.315 & 0.032 \\
\hline & $\begin{array}{l}\% \text { relative } \\
\text { accuracy }\end{array}$ & 93.6047 & 93.9225 & 94.3065 & 93.9616 & 93.6143 \\
\hline & S.D. & 1.0216 & 0.9895 & 0.9526 & 0.9886 & 1.0209 \\
\hline & \multicolumn{6}{|c|}{ Comutation time $=31.57 \%$ of that of method 1} \\
\hline \multirow{4}{*}{$\begin{array}{l}\text { 号 } \\
\text { 总 } \\
\sum_{2}^{0}\end{array}$} & Value of $n$ & 0.0275 & 0.028 & 0.0285 & 0.029 & 0.0295 \\
\hline & $\begin{array}{l}\% \text { relative } \\
\text { accuracy }\end{array}$ & 95.3326 & 95.5478 & 95.7166 & 95.5256 & 95.3282 \\
\hline & S.D. & 0.8980 & 0.8776 & 0.8576 & 0.8781 & 0.8 \\
\hline & \multicolumn{6}{|c|}{ Comutation time $=34.76 \%$ of that of method 1} \\
\hline
\end{tabular}

Referring to Table (1), the following conclusions are found:

1 - The value of Manning's roughness coefficient, $n$, of 0.025 , which is usually applied in design of Egyptian earthen canal, could be improper value and requires more studies. 
2- The value of the calibrated roughness coefficient in irregular channel is highly dependent on the applied method for geometric properties representation.

3- The accuracy of the newly developed method of geometric properties computation (method5) is $99.31 \%$ of the accuracy of method1, while requires computation time equal to 34.76 of that of method 1 .

4- The accuracy of the newly developed method (method5) is $99.92 \%$ of the accuracy of method2, while requires computation time equal to 70.56 of that of method2.

5- The calibrated value of roughness coefficient for the newly developed method (method) equals that for the method2 and slightly differs from that for the method1.

The results of applying the rectangular grid scheme of the method of characteristics using different values of distance interval with methodl and method4 of geometric properties computation are shown in Table (2) and Fig. (6).

Table (2) influence of using different values of distance interval with method 1 and method4

\begin{tabular}{|c|c|c|c|c|c|c|c|}
\hline \multirow{6}{*}{ 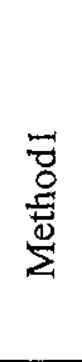 } & \multirow{3}{*}{ 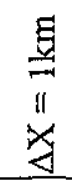 } & Value of $n$ & 0.0265 & 0.027 & 0.0275 & 0.028 & 0.0285 \\
\hline & & $\begin{array}{c}\% \text { relative } \\
\text { accuracy }\end{array}$ & 96.608 & 96.712 & 96.803 & 96.702 & 96.591 \\
\hline & & S.D. & 0.8071 & 0.7998 & 0.7842 & 0.7971 & 0.8033 \\
\hline & \multirow{3}{*}{$\frac{z}{\tilde{y}}$} & Value of $n$ & 0.0275 & 0.028 & 0.0285 & 0.029 & 0.0295 \\
\hline & & $\begin{array}{l}\% \text { relative } \\
\text { accuracy }\end{array}$ & 95.168 & 95.522 & 95.903 & 95.539 & 95.174 \\
\hline & & S.D. & 0.9084 & 0.8805 & 0.8416 & 0.8792 & 0.9076 \\
\hline \multirow{6}{*}{ 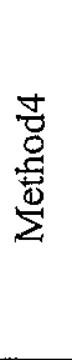 } & \multirow{3}{*}{ 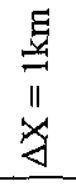 } & Value of $n$ & 0.029 & 0.0295 & 0.030 & 0.0305 & 0.031 \\
\hline & & $\begin{array}{l}\% \text { relative } \\
\text { accuracy }\end{array}$ & 94.671 & 94.870 & 95.079 & 94.864 & 94.664 \\
\hline & & S.D. & 0.9312 & 0.9138 & 0.8991 & 0.9151 & 0.9338 \\
\hline & \multirow{3}{*}{$\begin{array}{l}E \\
\mathbb{E} \\
\pi \\
\forall\end{array}$} & Value of $n$ & 0.031 & 0.0315 & 0.032 & 0.325 & 0.033 \\
\hline & & $\begin{array}{l}\text { \% relative } \\
\text { accuracy }\end{array}$ & 92.144 & 92.801 & 93.429 & 92.793 & 92.131 \\
\hline & & S.D. & 1.2854 & 1.2289 & 1.1762 & 1.2305 & 1.2881 \\
\hline
\end{tabular}

Referring to Table (2) and Fig. (6), it is concluded that:

1- The calibrated value of roughness coefficient is significantly on the used distance interval.

2- The decrease of the distance interval value using method 4 from $2 \mathrm{~km}$ to $1 \mathrm{~km}$ increases the accuracy of the results by 'a value of is $0.75 \%$, while the corresponding value using method 1 is $0.43 \%$. This means that the increase in the accuracy of the results by decreasing the value of distance step using method4 is higher than that of method1. 
3- For the case of $\Delta X=1 \mathrm{~km}$, a value of 0.005 change in the value of $\mathrm{n}$ trom its optimum value results in $0.10 \%$ and $0.20 \%$ decrease of the accuracy for methodl and method4; respectively. While, the corresponding values are $0.37 \%$ and $0.62 \%$; respectively for the case of $\Delta X=3 \mathrm{~km}$. This means that the improvement of the accuracy of the results by using optimum value of roughness coefficient depends on the method of geometric properties computation, especially for higher values of $\Delta \mathrm{X}$.

The results of applying the Leap-Frog scheme using $\Delta X=2 \mathrm{~km}$ and method1 of geometric properties computation are shown in Table (3) and Fig. (7):

Table (3) The results of applying the Leap-Frog scheme with methodl using $\Delta \mathrm{X}$ $=2 \mathrm{~km}$

\begin{tabular}{|c|l|l|l|l|l|}
\hline Value of $\mathrm{n}$ & 0.026 & 0.0265 & 0.027 & 0.0275 & 0.028 \\
\hline $\begin{array}{c}\text { \% relative } \\
\text { accuracy }\end{array}$ & 96.1091 & 96.2917 & 96.4732 & 96.3064 & 96.1112 \\
\hline S.D. $\cdots$ & 0.8458 & 0.8211 & 0.8014 & 0.8203 & 0.8449 \\
\hline
\end{tabular}

Referring to Tables (1 and 3) and Fig. (7), it is found that:

1 - The calibrated value of roughness coefficient for the Leap-Frog scheme is not equal to that of the rectangular grid scheme of the methof of characteristics.

2- The accuracy of the Leap-Frog scheme and the rectangular grid scheme of the method of characteristics are approximately equal.

3- The change of the value of $n$ from its optimum value produce decrease in the accuracy of the leap-Frog scheme is approximately to that of the rectangular grid scheme.

\section{Conclusions}

The conclusions of this research can be summarized as follows:

1- The value of Manning's roughness coefficient is could be different from the value of 0.025 , which is commonly used in the design of Egyptian earthen canal. Considerable attention should be paid in evaluating the value of roughness coefficient.

2- If an irregular channel is simulated as an equivalent regular channel or as a sequence of equivalent regular channel segments, the calibrated value of roughness coefficient will be larger than its true value.

3- The value of roughness coefficient is highly influenced by the used value of distance interval. Different value of distance interval yields to different value of roughness coefficient.

4- The sensitivity of the rectangular grid scheme of the method of characteristics to the used distance interval is significantly dependent on the used method of geometric properties computation. 
5- The sensitivity of the rectangular grid, scheme of the method of characteristics to the value of roughness coefficient is highly dependent on ${ }^{-2}$ the used method of geometric properties computation and the used value of distance interval.

6- The calibrated value of roughness coefficient is significantly affected by the applied numerical scheme.

7- The sensitivity of the rectangular grid scheme of the method of characteristics to the value of roughness coefficient is equal to that of the Leap-Frog scheme.

\section{References}

1- Ahmed, S.E. and Saad, M.B., " Prediction of natural channel hydraulic roughness ", Journal of Irrigation and Drainage Eng., ASCE, Vol. 118, No. 4, July/August, 1992.

2- Akan, B. C. and Yen, B. C., "Diffusion-wave flood routing in channel": networks ", Journal of Hyd. Div., ASCE, Vol. 107, No. HY6, June, 1981.

3- Amein, M. and Fang, C., "Implicit flood routing in natural channels ", Journal of Hyd. Div., ASCE, Vol.96, No. HY12, December, 1970.

4- Amein, M. and Chu, H.L., "Implicit numerical modeling of unsteady flows", Journal of Hyd. Div., ASCE, Vol. 101, No. HY6, June, 1975.

5- Atanov, G.A., Evseeva, E.G., and Meselhe, E.A., " Estimation of roughness profile in trapezoidal open channels.", Journal of Hyd. Eng., ASCE, Vol. 125, No. 3, March, 1999.

6- Bakry, M.F., Gates, T.K., and Khattab, A.F., " Field measured hydraulic resistance characteristics in vegetated-infested canals ", Journal of Irrigation and ". Drainage Eng., ASCE, Vol. 118, No. 2, March/April, 1992.

7- Bakry, M.F., " The hydraulic roughness of stable alluvial canals in Egypt ", Water Science, The National Water Research Center Magazine, Egypt, April, 1992.

8- Bakry, M.F., The hydraulic resistance performance of Egyptian main canals in operation private ", Journal of Eng. and Applied Science, Faculty of Eng., Cairo University, Vol. 44, No. 1, February, 1997.

9- Baltzer, R. A., and Lai, C., " Computer simulation of unsteady flows in waterways ", Journal of Hyd. Div., ASCE, Vol, 94, No. HY7, July, 1968.

10- El-Enany, M.A., " Characteristic models for unsteady flow in irregular channels ", Ph.D. dissertation, Hungarian Academy of Science, 1997.

11- El-Gamal, M.M., " Flow resistance in The Damitta branch of The Nile River ", Journal of Eng., Faculty of Eng., Mansoura University, Vol. 16, No. 1, June, 1991.

12- Fletcher, A.G. and Hamilton, W.S., " Flood routing in an irregular channel ", Journal of Mech. Div., ASCE, Vol. 93, No. EM3, June, 1967.

13- Fread, D.L. and Smith, G.F., "Calibration technique for 1-D unsteady flow , models", Journal of Hyd. Div., ASCE, Vol. 104, No. HY17, July, 1978.

14- French, R. H., " Open channel hydraulics ", McGraw-Hill Book Company, Singapore, 1986. 
15- Hatez, Y.I., El-Gamal, F.S., and Solıman, W.K., "Kiver Nile bed torms, resistance to flow and discharge prediction ", Water Science, The National Water Research Center Magazine, Egypt, October, 2000.

16- Hsu, M.H., Kuo, A.Y., and Kuo, J.T., " Procedure to calibrate and verify numerical models of estuarine hydrodynamics ", Journal of Hyd. Eng., ASCE, Vol. 125, No. 2, February, 1999.

17- Ify L. Nwaogazie," WICFEM- a Fortran program for solutions of Saint Venant stream flow equations ", Adv. Eng. Software, Vol. 7, No. 4, 1985.

18- Khatibi, R.H., Williams, J.R., and Wormleaton, P.R., "Identification problem of open-channel friction parameter ", Journal of Hyd. Eng., ASCE, Vol. 123, No. 12, December, 1997.

19- King, I. P., "Finite element model for unsteady flow routing through irregular channels", in finite element in water resources, Brebbia, C.A., et al., Pentech, London, 1976.

20- Lai, C. Schaffrank, R.W. and Baltzer, R.A., " An operational system for implementing simulation models: a case study ", Proc. of seminar on computational hydraulics, the 26th. Annual specially conference, hyd. division, ASCE, University of Maryland, Maryland, August, 1978.

21- Lai, C., "Numerical modeling of unsteady open channel flow ", Advances in Hydroscince V. T. Chow and B. C. Yen, eds., Vol.14, Academic Press, Orlando, Fla., 1986.

22- Lai, C., "Frictional resistance treatment in unsteady open channel flow simulation", Proc. of Int. conference on channel flow and catchment runoff : Centennial of Manning's rational formula, University of Virginia, Virginia, May, 1989.

23- Lal, M.W., " Calibration of river bed roughness ", Journal of Hyd. Eng., ASCE, Vol. 121, No. HY9, September, 1995.

24- Schaffranek, R.W. and Lai, C., " Friction-term response to boundary conditions type in flow models", Journal of Hyd. Eng., ASCE, Vol. 122, No. HY2, February, 1996:

25- Schuurmans, W., " Description and evaluation of program MODIS ", Journal of Irrigation and Drainage Eng., ASCE, Vol. 119, No. 4, July/August, 1993.

26- Weinmann, P.E., " Comparison of flood routing methods for natural rivers ", Report No. 2, Research reports, Monash university, Australia, 1977.

27- Zoppou, C. and Oneill, I. C.," Numerical methods and boundary conditions for the solution of unsteady flow problems ", Proc. of conference on hyd. eng., Sydney, Australia, October, 1981.

\section{Nomenclature}

$\begin{array}{ll}\text { A } & \text { cross-sectional area; } \\ B & \text { top width at the water level; } \\ B_{U} & \text { increase in top width corresponding to } y_{U} ; \\ C & \text { wave celerity }=(g A / B)^{0.5} \\ \text { E } & \text { gA }\left(\mathrm{S}_{\mathrm{o}}-\mathrm{S}_{\mathrm{f}}\right) ; \\ F & \mathrm{Q}^{2} / \mathrm{A}+\mathrm{gAY} \mathrm{Y}_{\mathrm{c} . \mathrm{g}} ;\end{array}$


$\mathrm{g}$ acceleration due to gravity;

n Manning's roughness coefficient;

P : wetted perimeter;

Q discharge;

$\mathrm{S}_{\mathrm{o}} \quad$ bed slope;

$\mathrm{S}_{\mathrm{f}} \quad$ friction slope;

$t \quad$ time;

$\mathrm{X} \quad$ longitudinal distance along the study reạch;

y water depth;

yu water depth above the expected water level;

$Y_{c . g}$ depth of centroid of water section below water surface;

$\Delta \mathrm{t} \quad$ time interval;

$\triangle \mathrm{X} \quad$ distance interval; and

$(\partial \mathrm{A} / \partial \mathrm{X})_{\mathrm{y}}$ rate of variation of $\mathrm{A}$ with respect to $\mathrm{X}$ when $\mathrm{y}$ is held constant.

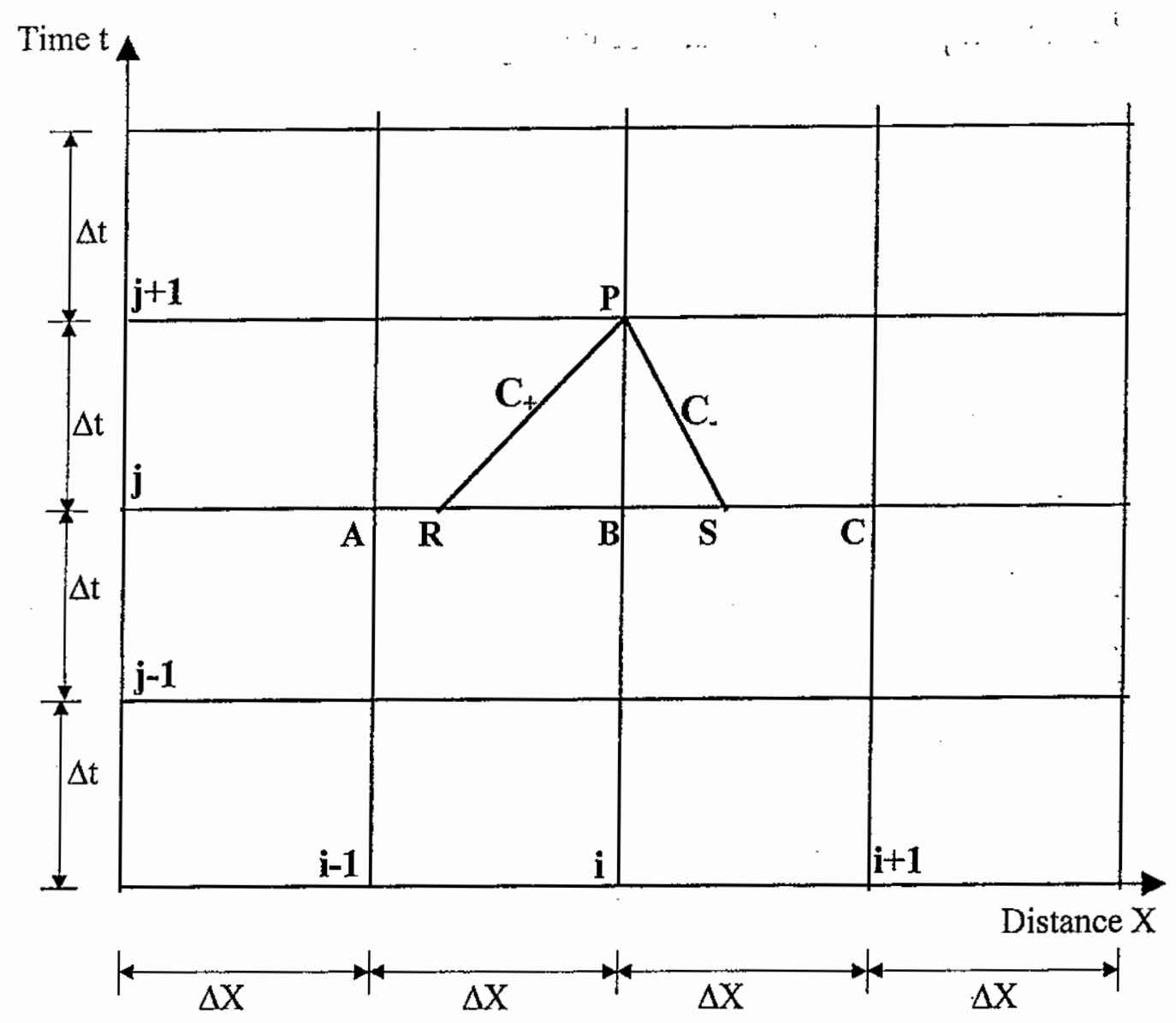

Fig. (1) Definition Sketch of Rectangular grid scheme of the method of characteristics and Leap-Frog scheme 


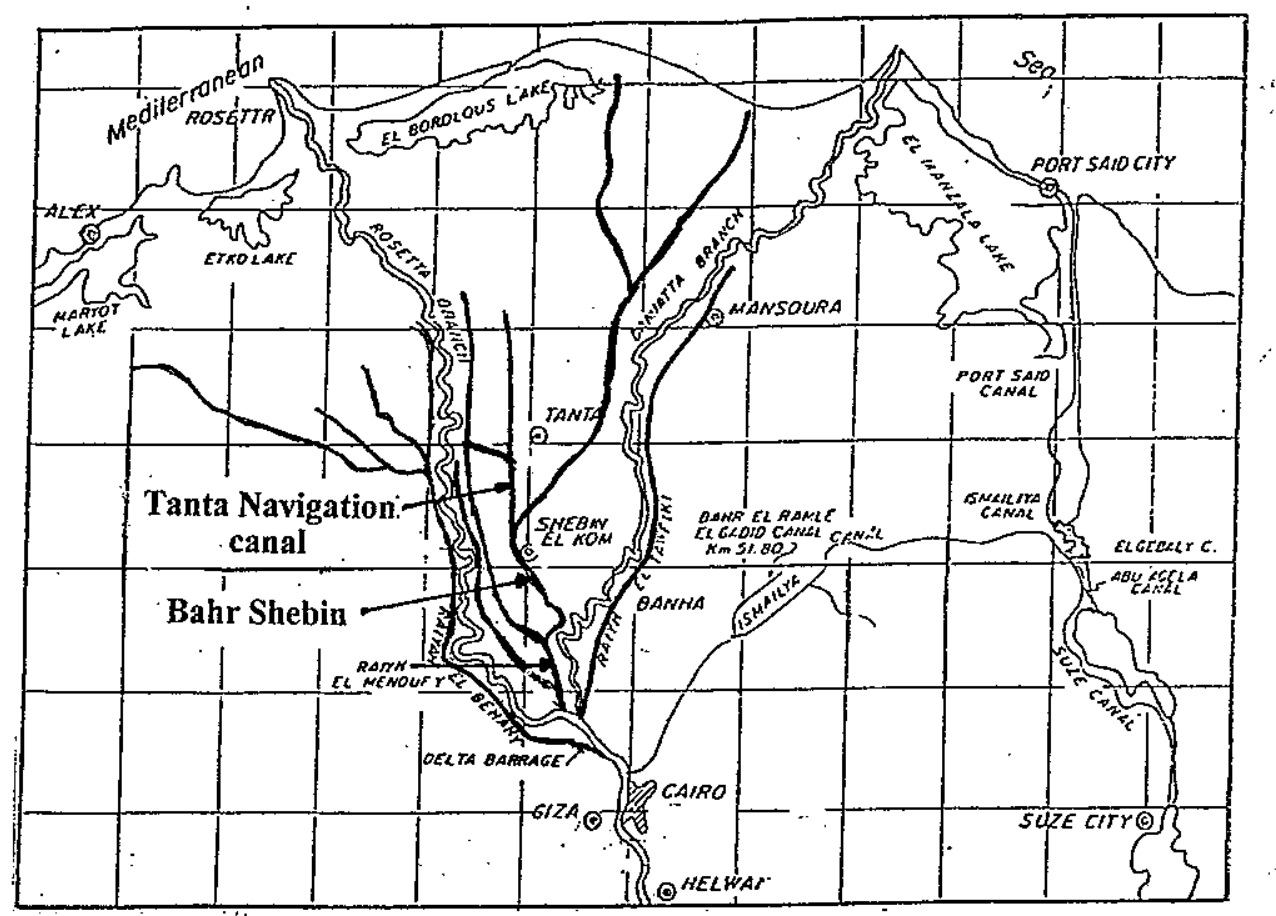

Fig.(2) General layout

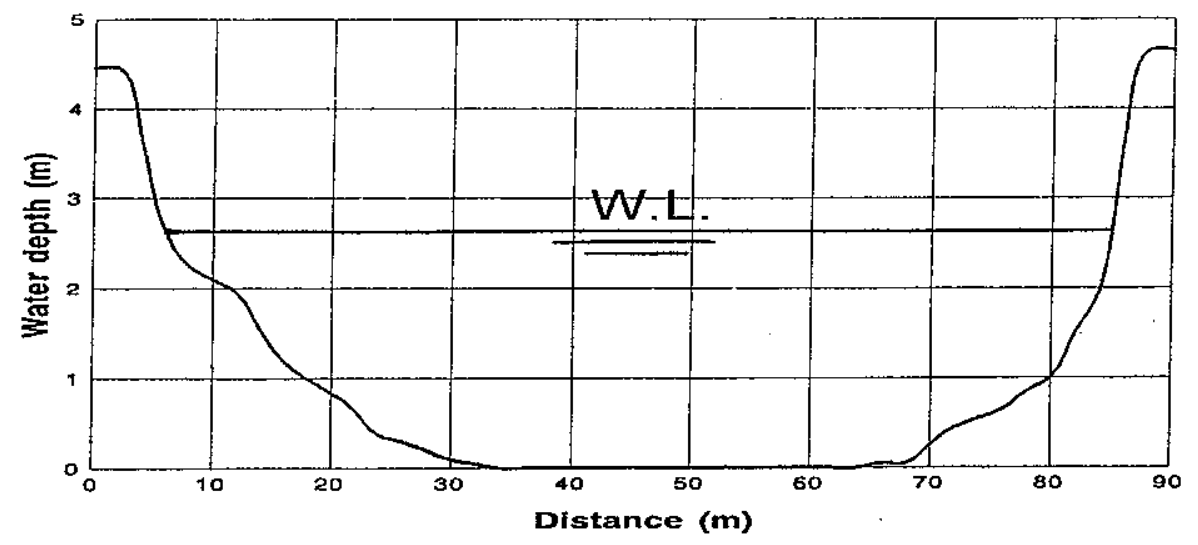

Fig.(3) Cross section at $\mathrm{Km}$. (3.00) 


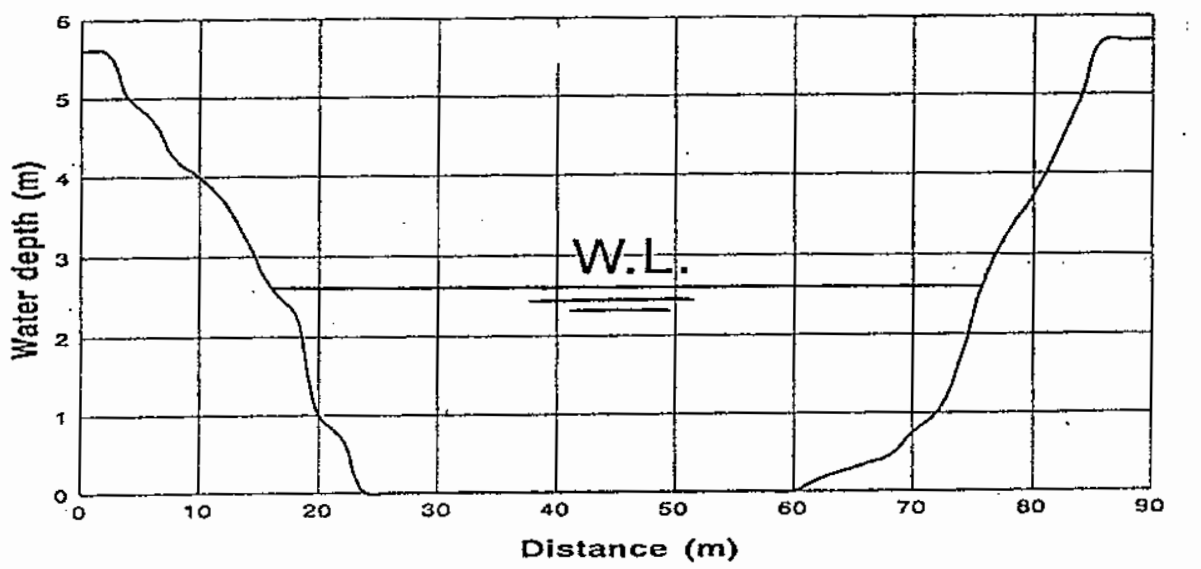

Fig.(4) Cross section at $\mathrm{Km}$. (9.00)

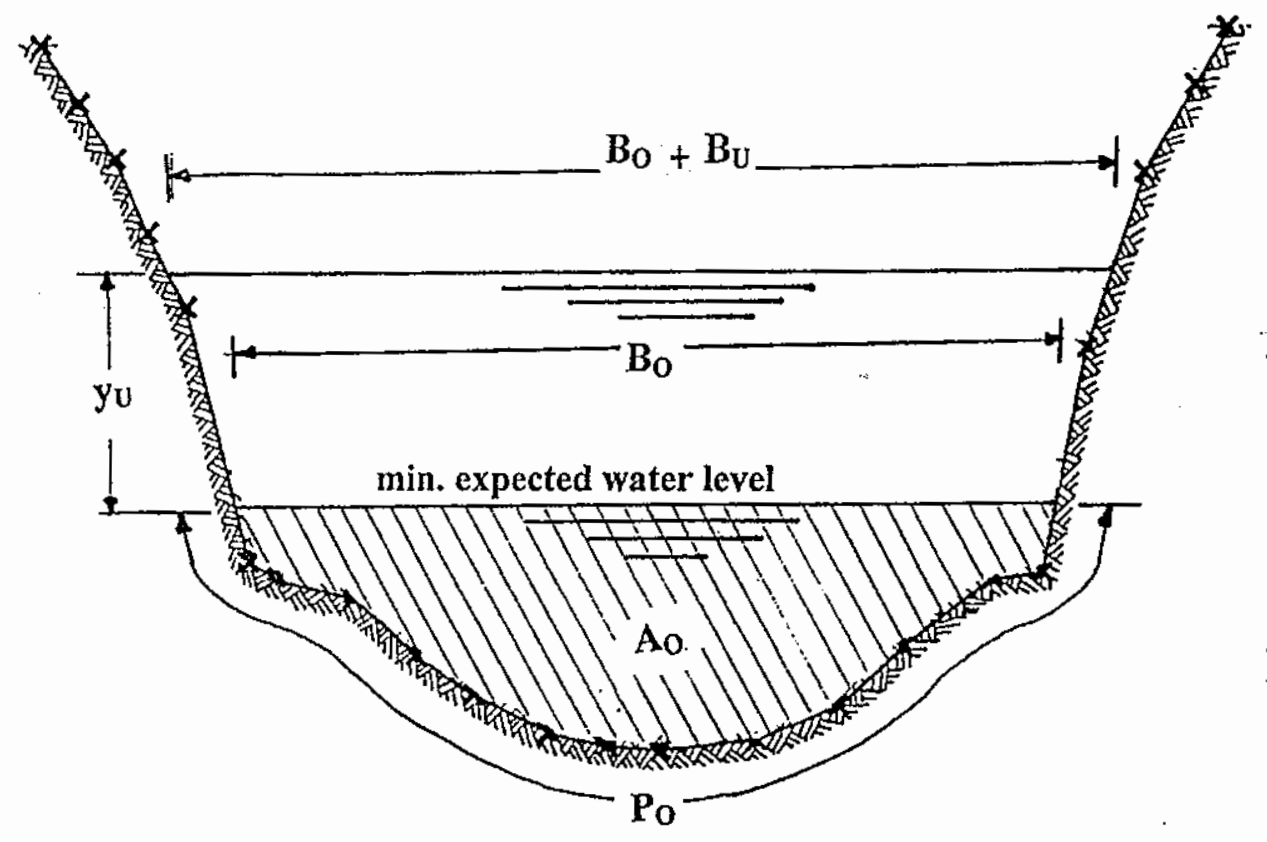

Fig. (5) Generalized sketch of a channel cross section illustrating method5 of geometric properties computation 


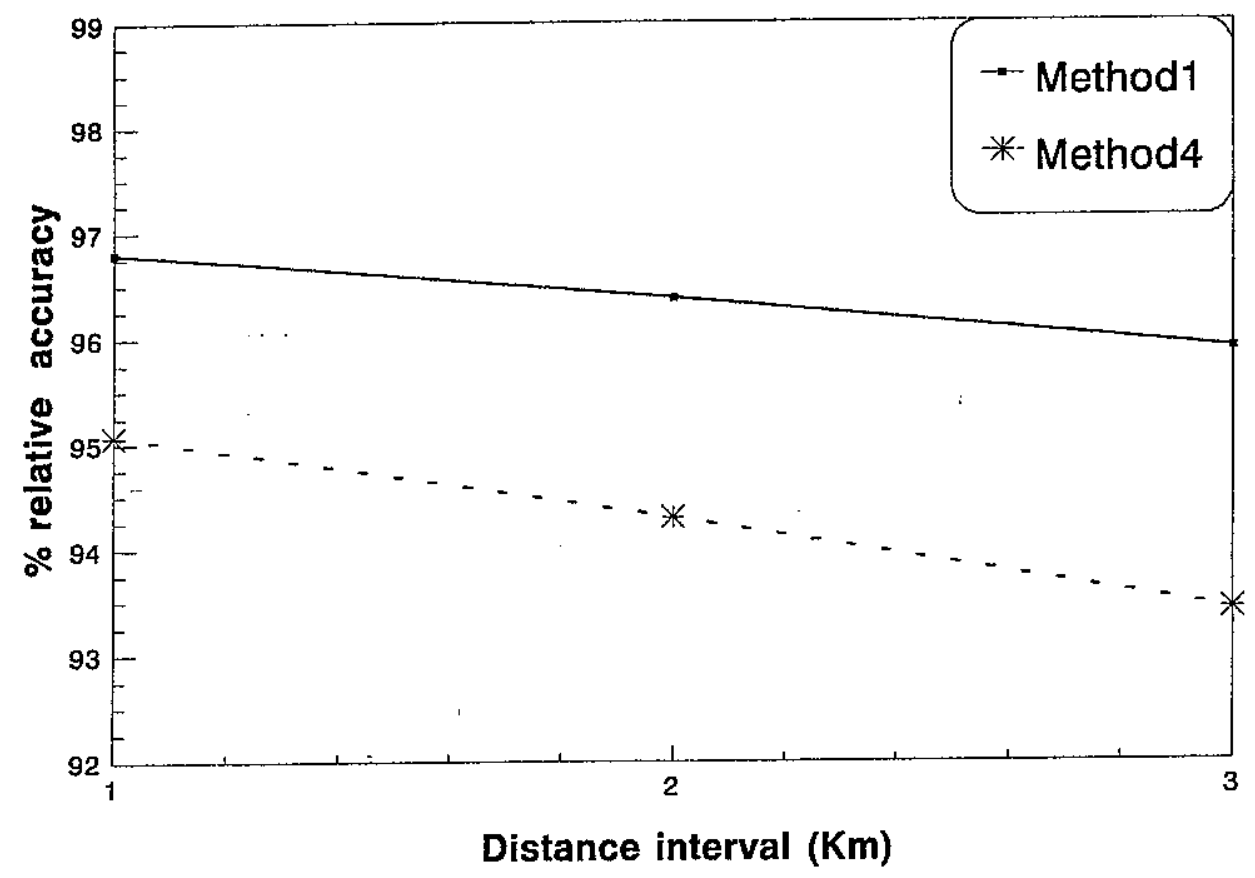

Fig.(6) Accuracy of Mehod1 and Method4

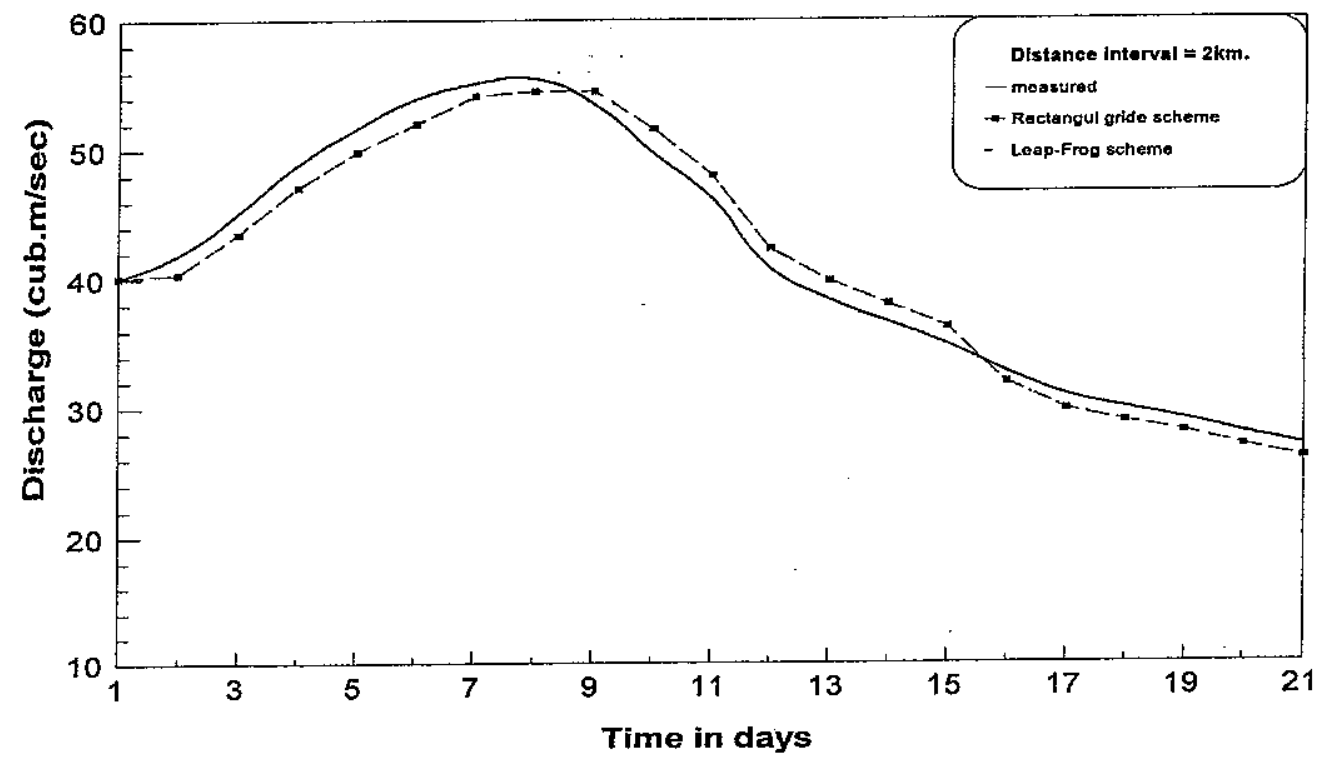

Fig.(7) Comparison between the measured and simulated discharge hydrographs. 


\title{
تأثير حساب الخواص الهنسية والنموذج الرياضي على معامل الإحتكاك للتسريان الإيز مستقر فى القنوات الغير منتظمة
}

\author{
/ / مصطفى عباس أحمد العناتى \\ كلية الهندسة بشبين الكوم - قسم الهندسة المدئية
}

معسامل الإحتكالك (المقاومة) يعتمد على الخواص الهنسية لقطاعات المجزى المائى و خو اص السريان وخواص السائل ويعتبر تحديد قيمة معامل الإحتكالك بدقة من أهم العناصر فى تصميم قطاعـات السـترع و المصارف وغالبا يتم إيجاد قيمة معامل الإحتكاك بالمعايرة. يوجد طرق مـتعددة لحساب الخو اص الهندسية للقطاعات فى التزرع الغير منتظمة. الغرض من هذا البحث هـو دراسة تأثير طريقة حساب الخو اص الهندسية للقطاعات و طريقة حل النموذج المرياضي على قيمة معامل الإحتكالكي المعاير فى الثرع الغير منتظمة القطاعات.

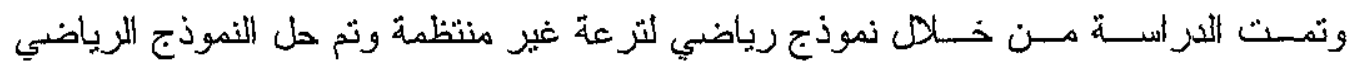
بأسـتخدام نموذج الشبكة المسنطيلة للطريقة المميزة وكذلك باستخدام نموذج ( Leap-Frog) لطــريقة الفــروق المحدةة. وتم فياس بيانات حقلية لقناة طنطا الملاحية و تمت مقارنة نتائج السنموذج الرياضدي مسع القيانسات الحقلية. ووجد أن طريقة حساب الخواص المندسية للقطاعـات لها ثأثنير كبيز على قيمة معامل الإحتكالك المعاير . وكذلك وجد أن طريقة حل

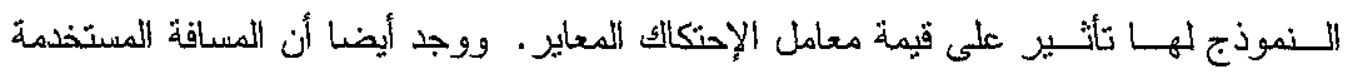
فى النموذج الرياضي نؤثر على قيمة معامل الإحتكاك المعاير. 